\title{
The Research of Chinese Anti-corruption Issues: Based on the Human Resource Management Perspective
}

\author{
Xiaode $\mathrm{Hu}^{1, \mathrm{a}}$ and Tingxuan $\mathrm{Zhu}^{1, \mathrm{~b}^{*}}$ \\ ${ }^{1}$ Zhejiang University of Finance and Economics, Hangzhou, China \\ a850781338@qq.com, b 1992813888.student@sina.com
}

Keywords: Anti-corruption; Government management; Human resource management.

\begin{abstract}
Since the 18th National Congress of the CPC, anti-corruption construction in China has made substantial progress under the Party's strong leadership with Xi Jinping as its General Secretary and has stroke a severe blow on people committed corruption and decadence. Common characteristics have been found through statistics of related materials on the investigated high-rank officials, including "59 year-old phenomenon", obvious trend of regionalization and collectivization not only in posts and departments, but also in reasons of crime, serious problems of promotion and retirement regardless of illness. Analyzing from the perspective of human resource management, this paper gives some suggestions on anti-corruption concerning post management, recruitment management, performance appraisal management and organizational culture construction, expecting to transform the psychology of officials from "dare not and cannot corrupt" to "do not want to corrupt".
\end{abstract}

\section{Introduction}

Since the 18th National Congress of the CPC and under the leadership of Xi Jinping, an anti-corruption construction movement of unprecedented resolution, strength and scale has presented a favorable trend. By March 31st, 2015, 102 high-rank officials above provincial and ministerial level, deputy corps level or major general level have been investigated and punished due to corruption, including "Big Tigers" such as Zhou Yongkang, Xu Caihou and Su Rong. Since the implementation of Eight Regulations of the Central Government, by March 31st, 2015, 58,172 issues violating the spirits of the regulations have been investigated nationwide, among which 78,627 persons were punished and 27,764 were given Party disciplinary sanctions [1].

As is stressed in Decision of the Central Committee of the Communist Party of China on Some Major Issues Concerning Comprehensively Deepening the Reform approved at the Third Plenary Session of the 18th CPC Central Committee, restrictions and supervisions on the execution of power concerning major leading cadres should be strengthened and improved. In terms of practice, due to the lack of restriction of powers and supervision, a few leading cadres use power as the tool of obtaining personal interests to vigorously execute "arbitrary decisions" even hide the truths from the masses [2]. This paper uses the investigated high-rank officials since the 18th National Congress of the CPC as the samples, collects relevant data for statistical analysis, digs the common characteristics of corruption, analyzes problems through the perspective of human resource management and gives suggestions on the prevention of corruption on the basis of analysis results.

\section{Corruption Characteristics of Officials in China}

Among the 102 investigated high-rank officials, 13 were from the central government agencies, 33 from military organs, 50 from provincial and municipal authorities and 6 from state-owned enterprises, including 1 of state level, 3 of deputy state level, 1 of provincial level, 35 of deputy provincial level, 6 of ministerial level, 24 of deputy ministerial level, 7 of deputy greater military regions level, 9 of corps level and 16 of deputy corps level. Some common characteristics of corruption have been found through the data involving age, region, post, criminal cause, working "regardless of illness" and so on. 
59-year-old Phenomenon. Among the 102 investigated officials, 90 made their ages public. By the time they were investigated, officials from 55 to 59 years old added up to 42, occupying $46.7 \%$ of those whose ages were made public and making the age group become that with frequent occurrence of corruption. 13 officials investigated were 58 years old and accounted for $12.7 \%$ of the total amount, while 14 were 59 years old and accounted for $13.7 \%$.

At present, it is ruled in China that the mandatory age for retirement of male civil servants is 60 years old. Before the 18th National Congress of the CPC, a lot of officials regarded retirement as a "protective talisman", thinking they would land safely and rest easy after retirement. Therefore, the one or two years before retirement have been the peak of committing crimes by officials, desirous of gaining more than "a barrel of gold". Meanwhile, most high-rank officials in China gather around the age of 50 to 60 years old. During this period, their official careers rise in a steady pace. Several years before retirement are the summit of official careers. Without supervision and control, some officials might use their status and power to violate the law and discipline and even reduce to corruption and decadence.

Obvious Trend of Regionalization and Collectivization. Among the 102 investigated officials, 92 made their native places public. 69 members of provincial, municipal level and corps level have concrete work regions. Officials whose native place is Shanxi Province were 15 and accounted for $16.3 \%$ of the total amount, followed by 15 of Shandong Province which accounted for $10.9 \%$ and seven of Jiangsu Province which accounted for $6.9 \%$. Of all the investigated officials from provincial and military organs, working places of 9 officials belong to Shanxi Province, occupying $13 \%$ of the total amount. Except for Shanghai, Ningxia and Jilin Province, the rest 28 provinces, autonomous regions, and municipalities all have investigated officials, among which 17 regions have more than two officials being investigated at the same time.

According to the collected materials, a well-connected relationship network of officials involves high-rank officials, rich merchants, lovers and family members. There has been an obvious trend of regionalization and collectivization among officials. For example, "Xishan Association" was a giant power-money empire made of high-rank officials working in Beijing whose native place was Shanxi Province and several identified vis-à-vis merchants. 7 Major involved high-rank officials included Ling Jihua, Ling Zhengce, Liu Tienan, Du Shanxue, Shen Weichen, Jin Daoming and Chen Chuanping who were investigated by the organization because of involvement in illegal crimes. The amount of money involved in the crime of Liu Tienan was up to 2.4 billion RMB. "Oil Clique" was an "oil organization" of the vested interest groups mainly consisted of CNPC and Sinopec. After the fall of Jiang Jiemin who used to be the Chairman and Secretary of Party Committee of CNCP Group, associated high-rank officials including Ran Xinquan, Wang Yongchun, Li Hualin and Wang Daofu were dismissed in succession in a week. High-rank officials who had benefit entanglement with "Xishan Association" and "Oil Clique" were also investigated and punished due to various behaviors that violated the law and discipline.

Centrality of Posts and Departments. Based on the statistical analysis of the final posts accounted for by the investigated officials, the author finds that the investigated officials are mainly distributed in posts of vice governors, vice president of the Political Consultative Conference, secretary of municipal Party Committee. Coverage of vice president of the Political Consultative Conference is much broader compared with other posts and the span of post levels are relatively larger. It has been found through the materials that a majority of law and discipline violation behaviors of the Political Consultative Conference vice presidents appeared in the undertaking of principals prior to the present position which had relatively collective power and networking. Therefore, the post of vice president of the Political Consultative Conference tends to be a transitional or transformational post. Although officials of provincial level on this post enjoy the treatment of the deputy provincial level officials, they do not have real power. Investigation of high-rank officials usually involves the whole body of administrations and has a specific requirement of caution, so transferring high-rank officials with the suspicion of corruption to this post may prevent them from further corrupting and benefit the 
work of future investigation. However, we are more willing to see problems solved in time and any idea of corruption be killed at its origin.

As to military organs, logistical support departments have been "the hardest hit area" of anti-corruption in army. Seven officials have been investigated and punished which accounted for $21.2 \%$ of the total army tigers. What follows the army is school, in which 5 officials were investigated and sanctioned and the number accounted for $16.2 \%$ of the total amount. The Chinese People's Liberation Army begins to adopt integration of joint services support. Each military region has set up joint service department to provide universal and specific supports of finance, goods and materials, oil and infrastructure barracks for army forces. Therefore, logistical support departments are more likely to contact land and materials. As certain rights are not restricted, it's more likely for them to bump into the red line. As to schools, problems concerning corruptive student recruitment of military academies, school lands and infrastructure projects are also particularly outstanding.

Centrality of Criminal Causes. Among the 102 investigated officials, 44 are still under investigation concerning the causes of their crimes suspicious of severe violation of laws and disciplines. The concrete criminal behaviors of the rest 58 officials have already been made public. It is found through the materials that the causes of officials' crimes mainly include: transactions of official positions, alliance of officials and merchants, keeping of mistresses, which respectively accounted for $36.3 \%, 60.8 \%$ and $37.3 \%$ of the total amount.

Transactions of official positions mainly reflect in securing interests for others in terms of cadre selection and appointment by taking advantage of post convenience and taking bribes. In essence, buying and selling official positions area combination of the common interests of rent setting and rent seeking parties. Sellers provide positions for buyers through formalized procedures and decision-making mechanisms while buyers provide money supporting for sellers in private. Alliance of officials and merchants is mainly reflected in securing interests for others in terms of business operations by taking advantage of post convenience and taking bribes. Keeping mistresses is mainly reflected in adultery, demoralization, corruption and degeneration. In terms of relationship networks, the relationship network of corruptive officials usually involves rich merchants. Some mistresses also have background of rich merchant identities. Officials are not allowed to run business. Superficially, projects are transacted by means of standard and tendering and bidding. Privately, officials ally with corporations to gain commissions, leading to the loss of state assets and even endangering life and property safety of the masses. Officials are unavoidably connected with merchants and the foothold of economic policies will ultimately reach corporations. However, there must be a clear boundary between the two parties which needs institutionalized constructions to support the "wall".

Severe Phenomena of Retirement with Illness and Promotion Regardless of Illness. Since the 18th National Congress of the CPC, the retirement with illness and promotion regardless of illness have become the issues of society. According to statistics, among the 102 officials, 9 retired with illness, which accounted for $8.8 \%$ of the total amount, while 54 were promoted regardless of illness, which accounted for $52.9 \%$. The possibilities of "illness" are mainly divided into 2 categories: firstly, covert whereabouts without showing themselves which needs the strengthening of a comprehensive patrolling and supervision; secondly, mutual protection of officials without any investigation which needs to strengthen the construction and perfection of evaluation systems and perform comprehensive and multilevel evaluations.

\section{Suggestions}

Set Posts Aiming At Specific Affairs and Complete Post Management Systems. Problems exist in some posts such as authority without responsibility, power greater than responsibility and no people for responsibility which are direct causes that lead to corruptions. The basic principle of post setting should aim at specific affairs. Posts should be set based on the targets and tasks of relevant departments with equal rights and liabilities as well as clear division of work. Post settings should be as few as possible to undertake tasks as many as possible and thoughts on "post settings aiming at 
specific persons" are absolutely beyond consideration [3]. Therefore, in the process of downsizing civil servants, government departments should take account of work practice to set posts by decomposing targets level by level. Responsibilities of each post should be processed tangentially without crossing or omitting. Useless and leisured posts ought to be cut resolutely.

Another major cause of corruption is the lack of scientific post analysis that leads to blind talent selection and recruitment. Post analysis will ultimately result in two basic documents of post instructions and post specifications, which are used as important support basis for "people selected for posts" and lay solid foundation for future human resource management. However, existing government departments haven't issued matching post instructions and post specifications and lack definitions of post responsibilities, requirements for qualifications and establishment of competency models, which will ultimately lead to the risk of "mismatching between people and posts" and extremely affect the normal work efficiency [4]. Therefore, it's urgent for government departments to organize specially-assigned persons to formulate post instructions and post specifications by spot investigations and interviews, making it a written system after expert reviews for further implementation so as to guarantee the smooth development of management work in the future.

Establish Scientific Performance Appraisal System. It is necessary to introduce balanced score card to government departments and key leading positions. Speaking of the implementation process, driven by missions, core values, prospects and strategies, strategic maps have been formed gradually from three levels including supporting measures-government construction, Party construction, financial fund; implementation path-economic development, people's livelihood improvement, social management, urban and rural construction, ecological environment, cultural development, reform and innovation; stakeholders - government, society and residents [5]. Targets are defined on the basis of such strategic maps. Indicators for performance appraisal concerning each level, target and task can be reflected according to the set of performance periods. In addition, due to the fact that key leading positions play a core role in the realization of organizational targets, balanced score card can also be introduced to its performance appraisal. Balanced core card should be designed according to the strategic map of a department from three levels including stakeholders, implementation path and supporting measures. Subdivide indicators to get practical appraisal scale [6]. Scores should be given by relevant sectors such as statistic bureau, inspection bureau and finance bureau based on the achievement of targets to ensure its objectivity.

Combine democratic centralism with social evaluation in performance appraisal of leaders on key posts. Anonymous evaluation can be added to the democratic appraisals by internal personnel so as to reduce the occurrence of herd behaviors and authority worships. Moreover, social evaluation can make democratic centralism more complete. By means of public opinion poll, democratic recommendation, democratic appraisal and publicity of actual performance, the masses can be a part of appraisers directly participate in the evaluation system of Party and government work [7]. Meanwhile, people's satisfaction should also be an indicator for appraisal. Once the inspection sector has received a certain amount of complaints and reports from the masses, it can cancel the appraisal of the correspondent cadre of that year. Thus, supervision and judgment rights are transferred to the people in a real sense and people become appraisers.

Attach great importance to performance process monitoring of major projects. In the daily process when officials exert their power, mistakes cannot be avoided if people only pay attention to the simple application of appraisal results after certain affairs and make praise and punishment only by means of justice. Performance process monitoring takes advantage of time-phased junctions, irregular examinations and project profit auditing which makes it easier to find out problems and solve them in time. In the process of power execution, key leaders perform standardized operations according to procedures. Moreover, the masses, social intermediary organs, mass media, superior competent departments, supervision sectors all play the role of performance monitoring subjects to do the supervision job and make ensure the performance process monitoring is smoothly implemented.

Try Hard to Promote Incorruption Culture Constructions. Leading cadres are required to set an example of incorruption. At the Second Plenary Session of the 18th Central commission for 
Discipline Inspection, General Secretary Xi Jinping pointed out "Anti-corruption constructions must be launched from leading cadres, especially major leading cadres. Major leading cadres refer to the principals who are supposed to undertake certain responsibilities and be strict with themselves so as to make it much easier to manage other works". Leading cadres inherit incorruption culture through their words and deeds while subordinates form a common value naturally and unconsciously. Therefore, leading cadres should set examples for others and insist on serving the people whole-heartedly [8]. They should maintain purity, take strict precautions against deviant behaviors and pay attention to the propagation effect brought by their works [9].

Strengthen constraint of behavior norms and promote incorruption culture oriented institutionalized constructions. Establish incorruption culture oriented systems of recruitment, training and performance appraisal. In recruitment system, use "incorrupt" as the primary requirement of recruitment criteria and inspect whether candidates conform to the value orientation of incorruption from multiple levels in the recruitment process. In training system, attach great importance to socialization, organize regular training aimed at incorruption for the whole personnel and give in-time evaluations, feedbacks and assess to the training results [10]. In performance appraisal system, use "incorruption" as a basic indicator, combine internal and external evaluations, cancel the performance appraisal qualifications as to those who fail to pass the indicator appraisals and combine the appraisal results with relevant state laws.

\section{Conclusion}

It can be seen from the materials that the corruption characteristics of high-rank officials nowadays in China mainly include: outstanding "59 year-old phenomenon" , serious trend of regionalization and collectivization, centrality of posts and sectors; the criminal causes mainly include transactions of official positions, alliance of officials and merchants, mistress keeping and obvious phenomena of promotion and retirement regardless of illness. The fundamental causes are as follows: failure at talent selection as well as inspection and prevention work; imperfect appraisal mechanism as well as lack of comprehensiveness and objectivity; problems existing in ruling culture construction and failure at systematic and institutional construction. It is expected that relevant sectors of the government can insist on the principles of placing cadres and talents under Party management; establish scientific post management, recruitment management and performance appraisal system; make great effort to promote incorruption culture construction so as to realize "compassion for the people, power for the people and interests for the people” in the real sense.

\section{References}

[1] Information on http://www.chinanews.com/gn/2013/12-04/5581480.shtml

[2] D.Wei: SHIJIAN, (2014) No.3, p.42.

[3] B.G.Zhang: Human Resources Development of China, (2015) No.19, p.87.

[4] W.M.Yin: Chinese Talents, (2012) No.5, p.9.

[5] Z.B.Fang: Human Resource Management of Public Sector (China Renmin University Press, China 2014).

[6] N.N.Tu: Commercial Times, (2011) No.5, p.112.

[7] L.Li and Z.F.Shang: Shandong Social Sciences, (2014) No.7, p.172.

[8] G.Y.Liu: Journal of Socialist Theory Guide, (2014) No.10, p.30.

[9] J.Yao and Z.L.Zhou: Changbai Journal, (2007) No.4, p.136.

[10] S.L.Zhang: Journal of Fujian Administration Institute, (2010) No.2, p.67. 